\title{
Apoptosis in Rheumatoid Arthritis Synovium
}

Gary S. Firestein, Michele Yeo, and Nathan J. Zvaifler

University of California, San Diego Medical Center, La Jolla, California 92093

\begin{abstract}
RA synovial tissue (ST) was studied to determine if and where apoptosis occurs in situ. Genomic DNA was extracted from 5 RA and 1 osteoarthritis ST samples. Agarose gel electrophoresis demonstrated DNA ladders characteristic for apoptosis from each tissue. In situ end labeling (ISEL) was used to identify DNA strand breaks consistent with apoptosis in frozen sections. 12 RA and 4 osteoarthritis ST were studied by ISEL and all were positive, but only 2 of 4 normal tissues were positive. The primary location of apoptotic cells was the synovial lining. Some sublining cells were also positive, but lymphoid aggregate staining was conspicuously absent. Immunohistochemistry and ISEL were combined and showed that the lining cells with DNA strand breaks were mainly macrophages, although some fibroblastlike cells were also labeled. Sublining cells with fragmented DNA included macrophages and fibroblasts, but $\mathbf{T}$ cells in lymphoid aggregates, which expressed large amounts of bcl2, were spared. DNA strand breaks in cultured fibroblastlike synoviocytes was assessed using ISEL. Apoptosis could be induced by actinomycin $D$, anti-fas antibody, IL-1, and TNF- $\alpha$ but not by IFN- $\gamma$. Fas expression was also detected on fibroblast-like synoviocytes using flow cytometry. Therefore, DNA strand breaks occur in synovium of patients with arthritis. Cytokines regulate this process, and the cytokine profile in RA (high IL-1/TNF; low IFN- $\gamma$ ) along with local oxidant injury might favor induction of apoptosis. (J. Clin. Invest. 1995. 96:1631-1638.) Key words: rheumatoid arthritis • apoptosis • fas • bcl-2 • synoviocyte
\end{abstract}

\section{Introduction}

Apoptosis, or programmed cell death (PCD), ${ }^{1}$ is a stereotypic method of cell death that can be distinguished from necrosis (1). During the early stages of apoptosis, nuclear chromatin condenses and DNA is digested into nucleosome-sized fragments. The cell volume decreases and small bodies containing nuclear debris and cellular organelles are surrounded by plasma

Address correspondence to Gary S. Firestein, University of California, San Diego School of Medicine, \#0656, 9500 Gilman Drive, La Jolla, CA 92093. Phone: 619-622-3908; FAX: 619-622-5546.

Received for publication 23 January 1995 and accepted in revised form 31 May 1995.

1. Abbreviations used in this paper: act D, actinomycin D; FLS, fibroblast-like synoviocytes; ISEL, in situ end labeling; MFC, mean fluorescence channel; OA, osteoarthritis; PCD, programmed cell death; IL-Ira, IL-1 receptor antagonist; ST, synovial tissue.

J. Clin. Invest.

(C) The American Society for Clinical Investigation, Inc.

0021-9738/95/09/1631/08 \$2.00

Volume 96, September 1995, 1631-1638 membrane and extruded from the cell. These are subsequently removed from the local environment via ingestion by phagocytic cells. Apoptosis can be induced by a variety of stimuli in vitro, including oxygen radicals, inhibitors of RNA transcription, heat shock, ethanol, cytokines, and anti-fas antibody $(1-5)$.

PCD is thought to play a critical role in many immune functions, including thymic selection and down-regulation of immune responses to viruses (6-8). Apoptosis is also involved in the regulation of cytokine production, and induction of PCD in macrophages causes processing of $\mathrm{IL}-1 \beta$ precursor to an active form $(9,10)$. It should not be surprising, therefore, that defective apoptosis has been related to autoimmunity. For instance, in the MRL/lpr strain of mouse that develops a disease like systemic lupus erythematosus, there is a defective fas gene that subsequently interferes with physiologic PCD $(11,12)$. This leads to massive lymphocyte accumulation, lymphadenopathy, and production of pathogenic antibodies, including antidouble stranded DNA antibodies. Elevated levels of soluble fas might contribute to delayed apoptosis and autoimmunity in SLE and administration of soluble fas to mice induces lupus-like manifestations (13). Another study suggested that the rate of peripheral blood lymphocyte apoptosis might be increased in SLE (14).

There is no information on PCD in the rheumatoid arthritis synovium. Previous reports have focused on neutrophil apoptosis in synovial fluid (15), and cells in inflammatory joint effusions show morphologic features of PCD (16). However, the reason for synovial hyperplasia, a characteristic change in rheumatoid arthritis joint tissues, and its relation to apoptosis is obscure. A simplified view of tissue growth is an imbalance between proliferation and cell death (along with a net influx of cells into the tissue from the blood in the case of a nonmalignant disease like rheumatoid arthritis). If anything, current notions suggest that apoptosis might be diminished in the synovium which, in conjunction with synovial lining cell proliferation, contributes to synovial hyperplasia (17). Therefore, we attempted to determine the extent of PCD in RA synovium anticipating that we would find only limited evidence. To our surprise, DNA fragmentation consistent with apoptosis is quite prevalent in RA synovium, especially in intimal lining macrophage- and fibroblast-like cells. $\mathrm{T}$ cells in lymphoid aggregates express abundant bcl-2 and are spared. Furthermore, PCD can be induced in cultured fibroblast-like synoviocytes (FLS) by cytokines present in inflamed joints.

\section{Methods}

Reagents. Reagents were obtained from the following sources: RNase A, DNase I, Klenow polymerase, DTT, digoxigenin-11-dUTP, antidigoxigenin antibody conjugated to alkaline phosphatase, nitroblue tetrazolium (NTB), and 5-bromo-4-chloro-3-indolyl phosphate (BCIP) (Boehringer Mannheim Biochemicals, Indianapolis, IN); anti-bcl-2 antibody, anti-CD68 antibody, anti-CD45RO antibody (-Dako Corp., Carpinteria, CA); proteinase $\mathrm{K}$, actinomycin $\mathrm{D}$ (act D), methyl green, Tris base, boric acid, EDTA, sodium acetate, sodium chloride, ethidium 
bromide, agarose, collagenase (Sigma Chemical Co., St. Louis, MO); deoxynucleotide triphosphates (Pharmacia Diagnostics AB, Uppsala, Sweden); diaminobenzidene (DAB) (Research Genetics, Huntsville, AL); tritiated thymidine 5 '-phosphate ( $30 \mathrm{Ci} / \mathrm{mmol}$ ) (Amersham Corp., Arlington Heights, IL).

Cytokines. All recombinant cytokines were purchased from Genzyme Corp., Cambridge, MA (recombinant hIL- $1 \beta$ [sp act $>5 \times 10^{7}$ $\mathrm{U} / \mathrm{mg}$, purity $>98 \%$ ], rhIFN $-\gamma$ [sp act $2.5 \times 10^{7} \mathrm{U} / \mathrm{mg}$, purity $>99 \%$ ] and rhTNF- $\alpha$ [sp act $2 \times 10^{9} \mathrm{U} / \mathrm{mg}$, purity $>98 \%$ ]).

Synovial tissue. Synovial tissue was collected at the time of total hip or knee replacement from patients with osteoarthritis (OA) or RA (18). One RA tissue was obtained by percutaneous synovial biopsy as previously described (19). Four normal synovial tissues were harvested post-mortem from patients without previous history of arthritis. The post-surgical specimens were placed on ice and subsequently snap frozen within $1 \mathrm{~h}$. The post-mortem specimens were processed within 12$24 \mathrm{~h}$ after death.

Synoviocyte culture. Synovial cells were isolated by enzymatic dispersion of synovial tissues as previously described (18). Briefly, the tissues were minced and incubated with $1 \mathrm{mg} / \mathrm{ml}$ collagenase in serumfree DME (GIBCO, Grand Island, NY) for $2 \mathrm{~h}$ at $37^{\circ} \mathrm{C}$, filtered through a nylon mesh, extensively washed, and cultured in DME supplemented with $10 \%$ FCS (endotoxin content $<0.006 \mathrm{ng} / \mathrm{ml}$; GIBCO), penicillin, streptomycin, and L-glutamine in a humidified $5 \% \mathrm{CO}_{2}$ atmosphere. After overnight culture, nonadherent cells were removed and adherent cells were cultivated in DME plus $10 \%$ FCS. At confluence, cells were trypsinized, split at a 1:3 ratio, and recultured in medium. Synoviocytes were used from passages 3 through 9 in these experiments, during which time they were a homogeneous population of FLS ( $<1 \%$ CD11b, $<1 \%$ phagocytic, and $<1 \%$ Fc- $\gamma$ RII receptor positive).

Method for harvesting tissue DNA. About $100 \mathrm{mg}$ of synovial tissue (ST) was lysed on ice for $30 \mathrm{~min}$ in $10 \mathrm{mM} \mathrm{NaCl}, 10 \mathrm{mM}$ TrisHCl pH $7.5,1 \mathrm{mM}$ EDTA plus $0.2 \%$ Triton-X. The nuclei were pelleted at $13,000 \mathrm{~g}$ at $4^{\circ} \mathrm{C}$ for $15 \mathrm{~min}$. The supernatant (containing low molecular weight DNA) was transferred to a fresh tube. RNase A (final concentration $50 \mu \mathrm{g} / \mathrm{ml}$ ) was added to the supernatant and incubated at $37^{\circ} \mathrm{C}$ for $1 \mathrm{~h}$. Proteinase $\mathrm{K}$ ( final concentration $100 \mu \mathrm{g} / \mathrm{ml}$ ) was then added and incubated for an additional $4 \mathrm{~h}$ at $50^{\circ} \mathrm{C}$. The DNA was extracted with phenol/chloroform twice and precipitated from the aqueous phase overnight after the addition of 0.1 vol of $3 \mathrm{M}$ sodium acetate and $2.5 \mathrm{vol}$ $100 \% \mathrm{EtOH}$. DNA was recovered by centrifugation at $13,000 \mathrm{~g}$ at $4^{\circ} \mathrm{C}$ for $20 \mathrm{~min}$ and washed once with $70 \% \mathrm{EtOH}$. The DNA pellet was resuspended in Tris-EDTA buffer. 5-15 $\mu \mathrm{g}$ of DNA from each sample was subjected to electrophoresis on $1.5 \%$ agarose gel containing ethidium bromide and visualized under UV illumination.

In situ end labeling (ISEL) assay. Fragmented DNA was detected in cell nuclei using a modification of previously described methods (20, 21 ). Frozen section of synovial tissue (5-6 $\mu \mathrm{m}$ thick) were placed onto poly-L-lysine-coated slides and air dried for at least $2 \mathrm{~h}$. For studies of fibroblast-like synoviocytes, cells were grown to confluency in 4chamber Lab-Tek slides (Nunc, Inc., Naperville, IL) and treated with apoptosis-inducing agents for $16 \mathrm{~h}$. The tissue sections or FLS were then fixed with EtOH/acetic acid 3:1 for $10 \mathrm{~min}$ at room temperature and washed with buffer 1 (see below) for $5 \mathrm{~min}$. The slides were then air dried for at least $2 \mathrm{~h}$. 10-15 $\mu \mathrm{l}$ of DNA polymerase mix were added to each section and incubated at room temperature for $1 \mathrm{~h}$. The sections were washed with buffer 1 (see below) for $5 \mathrm{~min}$ at room temperature followed by a wash in buffer 2 for $5 \mathrm{~min}$. Alkaline phosphatase conjugated antidigoxigenin antibody was diluted to 1:500 in buffer 2 and 15$20 \mu \mathrm{l}$ was applied to each specimen. The slides were incubated at $37^{\circ} \mathrm{C}$ for $2 \mathrm{~h}$ in a humidified chamber and then washed with buffer 1 for 5 $\min$. They were then equilibrated with buffer 3 for $5 \mathrm{~min}$ and the color reagent (NBT + BCIP) was added to the specimens. After $\sim 30 \mathrm{~min}$ the slides were washed with distilled water, counterstained with eosin or methyl green, and dehydrated with graded alcohol washes. The developing reagent gave a dark purple color for positive signals. Buffers: $10 \times$ DNA polymerase buffer $=0.5 \mathrm{M}$ Tris $\mathrm{HCl}$ pH 7.5, $0.1 \mathrm{M} \mathrm{MgCl}_{2}$, $1 \mathrm{mM}$ DTT; $10 \times$ nucleotide $\mathrm{mix}=1 \mathrm{mM}$ each of dATP, dCTP, and dGTP, $0.4 \mathrm{mM}$ dTTP; DNA polymerase mix $=10 \times$ DNA pol buffer
$(2 \mu \mathrm{l}), 10 \times$ nucleotide mix $(2 \mu \mathrm{l}) ; 100 \mu \mathrm{M}$ digoxigenin-11-dUTP (0.5 $\mu \mathrm{l})$, Klenow polymerase $(2 \mu \mathrm{l}[2 \mathrm{U}])$, water $(13.5 \mu \mathrm{l})$; buffer $1=100$ $\mathrm{mM}$ Tris $\mathrm{HCl}$ pH 7.5, $150 \mathrm{mM} \mathrm{NaCl}$; Buffer $2=0.5 \%$ blocking agent in buffer 1; buffer $3=100 \mu \mathrm{M}$ Tris $\mathrm{HCl}$ pH $9.5,100 \mu \mathrm{M} \mathrm{NaCl}, 50$ $\mu \mathrm{M} \mathrm{MgCl}{ }_{2}$

Quantification of ISEL assay. For FLS cultured in chamber slides, the percentage of positive cells was determined for each condition by counting 300-500 cells in the chambers. A semiquantitative scale was used to estimate the degree of ISEL staining in tissue sections that had been counterstained with methyl green to distinguish ISEL-positive and -negative cells. Four areas were reviewed by a blinded investigator: the synovial intimal lining, the sublining, blood vessels, and lymphoid aggregates. The extent of staining in the area was estimated and scored as follows using a previously established semiquantitative method (22): 0 $=$ negative $; 1+=$ rare positive cells in a specific region; $2+=$ scattered clusters of positive cells in a specific region; $3+=$ moderate staining in a specific region; and $4+=$ extensive staining in a specific region.

Immunohistochemistry in combination with ISEL. Because antiCD68 and -CD45RO antibodies did not bind to ethanol:acetic acid treated sections, double staining studies were performed on acetone fixed tissue $\left(5 \mathrm{~min}\right.$ at $\left.4^{\circ} \mathrm{C}\right)$. This fixative optimized immunoperoxidase staining, although the ISEL signal was not as well localized to nuclei (perhaps due to leaching of DNA fragments into the cytoplasm). The ISEL procedure was then performed as above. However, before addition of antidigoxigenin antibody, standard immunohistostaining was performed. The primary antibody (anti-bcl-2, -CD68, or -CD45RO) was added for $60 \mathrm{~min}$ at room temperature. The control $\mathrm{mAb}$ was an isotype matched control at the same concentration. After two washes in PBS plus $0.1 \%$ BSA, biotinylated horse anti-mouse antibody (Vector Laboratories, Inc., Burlingame, $\mathrm{CA}$ ) in $10 \%$ human $\mathrm{AB}$ serum was added for $30 \mathrm{~min}$. The slides were washed and endogenous peroxidase was depleted with $0.3 \%$ hydrogen peroxide in PBS for $15 \mathrm{~min}$. The slides were then washed extensively, incubated with $\mathrm{ABC}$ horseradish peroxidase complex (Vector Laboratories, Inc.) for $30 \mathrm{~min}$, and developed with diaminobenzidine. After this step, the antidigoxigenin antibody was added and the ISEL assay was completed as above. The doublestained slides were counterstained with either eosin or $0.1 \%$ methyl green.

${ }^{3} \mathrm{HdTr}$ nuclear fragmentation assay. RA FLS were seeded at $10^{4}$ cells/well in a 96 -well microtiter plate. The cells were cultured at $37^{\circ} \mathrm{C}$ and $5 \% \mathrm{CO}_{2}$ for $2 \mathrm{~d}$. On the third day, $10 \mu \mathrm{Ci} / \mathrm{ml}$ per well of ${ }^{3} \mathrm{HdTR}$ was added to each well and incubated overnight. The cells were then treated with different concentrations of cytokines or antibodies for $8 \mathrm{~h}$ or act $\mathrm{D}$ for $4 \mathrm{~h}$ and then lysed by two rounds of freeze-thaw cycles. Lysed cells and media were aspirated onto fiber glass filters using a cell harvester. The filters were washed to remove unincorporated nucleotides and counted in a liquid scintillation counter. All points were done in triplicates. Percent specific fragmentation was calculated as follows: ( $S$ - E) $\times 100 / \mathrm{S}$, where $\mathrm{E}=$ retained $\mathrm{cpm}$ on the filter in the presence of cytokine and $S=$ retained cpm on the filter in the medium control (23). A high percentage of specific fragmentation indicates that DNA was incorporated into low molecular weight fragments that were not retained on the filter.

Flow cytometry. FLS $\left(1-2 \times 10^{5}\right)$ were cultured in 6-well plastic dishes (Costar Corp., Cambridge, MA) in DME-10\% FCS. Cells were harvested with $5 \mathrm{mM}$ EDTA at $4^{\circ} \mathrm{C}$ and stained with anti-fas or control antibody (Kamiya Biomedical Co., Thousand Oaks, CA) as previously described (18). Phycoerythrin-conjugated $\mathrm{Fab}_{2}$ anti-mouse IgG (Tago Inc., Burlingame, CA) was used as a secondary antibody. An isotype matched $\mathrm{mAb}$ was used as negative control. Induction of fas expression by cytokines was calculated from the mean fluorescence channels (MFC) as follows: relative $\mathrm{MFC}=\left(\mathrm{MFC}_{\text {cytokine }}-\mathrm{MFC}_{\mathrm{lgG}}\right) /\left(\mathrm{MFC}_{\mathrm{m}}\right.$ $-\mathrm{MFC}_{\mathrm{IgG}}$ ). A cell was defined a positive if its $\mathrm{MFC}$ was $>98 \%$ of cells stained with the control antibody.

Statistical analysis. Data were analyzed using the paired Student $t$ test and are presented as mean \pm SEM.

\section{Results}

$R A$ synovium contains fragmented DNA. Initial studies were performed to determine if DNA isolated from RA synovium 


\section{Apoptosis in Arthritic Synovium}

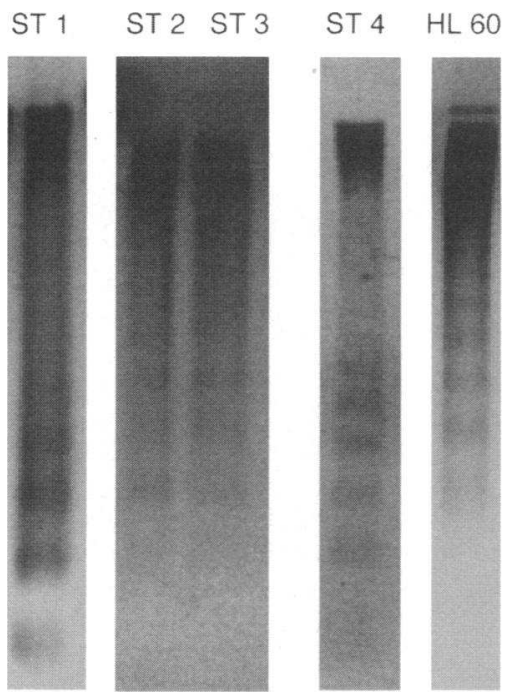

Figure 1. Apoptosis in synovium from arthritis patients. A DNA ladder is readily visualized in DNA from four synovial tissues $(\mathrm{RA}=S T 1,3,4$; $\mathrm{OA}=S T$ 2). Act $\mathrm{D}-$ treated HL-60 cells are shown as a positive control. The figure shows a negative image of the ethidium-stained gel.

contained nucleosomal DNA. Low molecular weight DNA was isolated from whole synovial tissue extracts and separated by agarose gel electrophoresis. Six tissues processed were in this manner (5 RA and $1 \mathrm{OA}$ ) and each showed the characteristic DNA ladder observed in apoptosis (see Fig. 1 for representative examples).

In situ detection of DNA fragmentation. To determine which cells contained fragmented DNA in synovial tissue, an ISEL assay was used. This assay was first validated with HL60 cells. Apoptosis was induced in the HL60 cells with act D under conditions that produced a DNA ladder (Fig. 1). Act D-treated cells were air-dried on slides and tested in the ISEL assay. These cells were strongly ISEL-positive while control HL60 cells cultured without act $\mathrm{D}$ were negative (data not shown). The same method was then applied to frozen sections of synovial tissue. $12 \mathrm{RA}, 4 \mathrm{OA}$, and 4 normal synovia were studied. All arthritis tissues but only two of the four normal specimens were positive. Fig. 2 shows a representative example of an RA tissue. Many apoptotic cells were located in the synovial intimal lining. In some tissues, sublining cells were also positive, including interstitial cells and vascular endothelium. However, lymphoid aggregates were conspicuously negative (see Fig. 3 $B$ for an example). The amount of DNA fragmentation was significantly greater in RA lining and sublining compared with $\mathrm{OA}$ and normal synovium (Table I). As an additional control, a frozen section of an ISEL-negative normal tissue was treated with DNase I $(0.005 \mathrm{U} / \mathrm{ml}$ in $20 \mathrm{mM}$ TrisHCl $\mathrm{pH} 7.6,50 \mathrm{mM}$ $\mathrm{NaCl}, 1 \mathrm{mM}$ DTT for $1 \mathrm{~min}$ at room temperature) to nick DNA. An ISEL experiment on this tissue was then markedly positive in the sublining and intimal lining cells (data not shown). To confirm the specificity of the assay, ISEL was also performed on frozen sections of normal human liver and lymph node and the results were negative (data not shown).

A potential concern about the ISEL studies is that DNA strand breaks might actually occur ex vivo (after surgery and before snap freezing). To address this possibility, a percutaneous synovial biopsy from an RA patient was examined using ISEL. That tissue was also ISEL-positive, and staining was equivalent to most other RA tissues even though it was pro- cessed and frozen within a minute of procurement. In a separate experiment, a portion of one RA synovium obtained at joint replacement surgery was snap frozen within 20 min after removal from the joint while a second block from the same tissue was maintained at room temperature for $2 \mathrm{~h}$. Frozen sections of both blocks were subsequently studied using the ISEL technique and showed equivalent degrees of staining. Taken together, these experiments strongly suggest that the data obtained with surgical specimens reflects the situation in vivo.

Identification of cells containing fragmented DNA. Immunohistochemistry was combined with ISEL to determine the phenotype of apoptotic cells. As shown in Fig. $3 \mathrm{~A}$, cells expressing the macrophage antigen CD68 constituted the majority of the ISEL-positive cells in the intimal lining, especially in the most superficial layer. The presence of some CD68-negative/ ISEL-positive cells in the lining suggested that FLS had DNA strand breaks consistent apoptosis. A regular finding, as noted above, was the lack of ISEL staining of CD45RO-positive T cells in lymphoid aggregates, even though ISEL-positive cells frequently surrounded the aggregates (Fig. $3 B$ ). Some individual CD45RO-negative/ISEL-positive cells were scattered throughout the sublining, suggesting that only the $\mathrm{T}$ cells in aggregates were protected from apoptosis.

ISEL-negative cells in lymphoid aggregates express bcl-2. Because $\mathrm{T}$ cells in lymphoid aggregates showed little evidence of DNA fragmentation, immunohistochemistry was performed to determine if they expressed the oncogene bcl-2, which protects cells from apoptosis (24-26). Bcl-2 expression was low or absent in some tissues, but, when present, it was primarily found in sublining lymphoid aggregates (Fig. 4).

Apoptosis in cultured FLS. The presence of CD68-negative apoptotic cells in the synovial lining prompted an analysis of the regulation of FLS apoptosis in vitro. Using the ISEL assay on resting FLS cultured in chamber slides, apoptosis was shown to be very low. IFN- $\gamma$ alone had a minimal effect, while antifas antibody, IL- $1 \beta$, TNF- $\alpha$, and act D caused significant DNA fragmentation (Table II). OA- and RA-derived FLS were both susceptible to induction of DNA strand breaks. IFN- $\gamma$ in combination with these factors significantly reduced FLS apoptosis, while TNF- $\alpha$ was additive with act D. To confirm the effect of each apoptosis-inducing factor, a second assay $\left({ }^{3} \mathrm{HdTr}\right.$ nuclear fragmentation) was used to quantify DNA fragmentation in cultured FLS. As with the ISEL method, this technique showed that anti-fas, IL- $\beta$, TNF- $\alpha$, and actinomycin D each caused DNA fragmentation (Fig. 5).

Surface fas expression on FLS. Since anti-fas antibody induced DNA fragmentation in FLS, fas expression was determined on these cells using flow cytometry. Many FLS constitutively expressed fas protein on the cell surface (see Fig. 6 for a representative experiment $[n=7$; four RA and three OA]). There were no significant differences between OA and RA FLS with regard to the level of surface fas expression on resting synoviocytes. To determine if key cytokines present in inflamed synovial tissue could regulate fas expression, six of the FLS lines (three RA and three OA) were cultured with IL-1 $\beta$ (1 $\mathrm{ng} / \mathrm{ml})$ or TNF- $\alpha(100 \mathrm{ng} / \mathrm{ml})$ for 16 and $24 \mathrm{~h}$. The results for OA and RA FLS were similar and were pooled. As shown in Table III, TNF- $\alpha$ significantly increased surface fas expression at both time points. Although IL- $1 \beta$ caused a slight increase, the difference did not reach statistical significance.

\section{Discussion}

Rheumatoid arthritis is a symmetric inflammatory arthritis marked by synovial lining hyperplasia, angiogenesis, and 


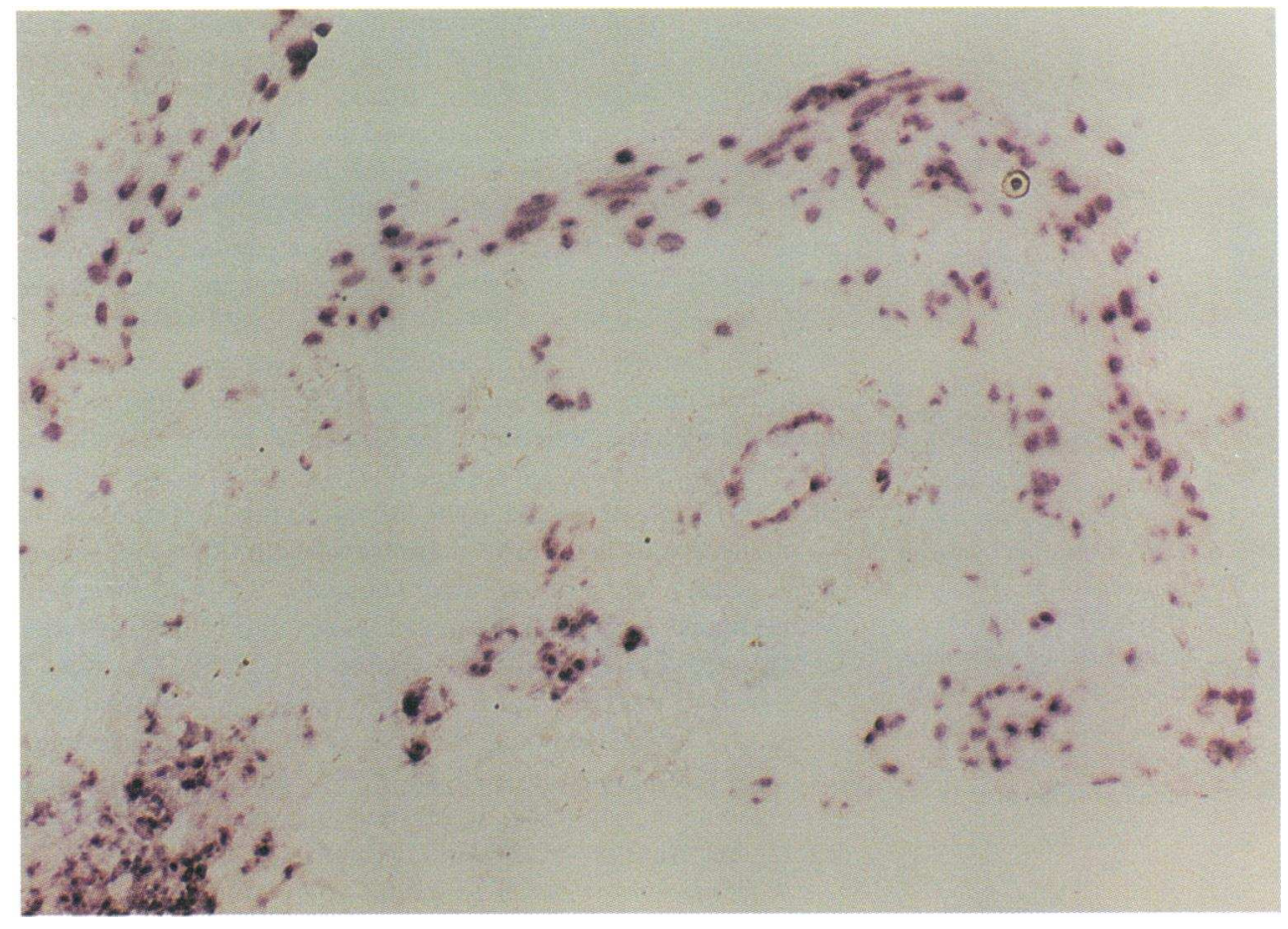

Figure 2. ISEL assay on a frozen section of RA synovial tissue. The tissue was counterstained only with eosin, so that normal nuclei are not visualized. Nuclei with fragmented DNA (dark nuclei) are readily distinguished. The tissue section was photographed at a magnification of 200 . sublining infiltration of the synovium with mononuclear cells (27). This histologic picture presumably results from an imbalance between forces that increase tissue cellularity (e.g., recruitment from blood and local proliferation) and those that decrease tissue cellularity (e.g., cell death and emigration into the blood, lymphatics, or synovial fluid). The accumulation of cells in RA synovium appears to result from a cytokine milieu rife with chemoattractants and growth factors as well as enhanced vascular adhesion molecule expression (22, 27-29). However, little is known about how cells leave the joint, particularly the role that local apoptosis might play in synovial homeostasis.

In PCD, nuclear DNA fragments into integer multiples of 200-base nucleosomes. Using gel electrophoresis, this can be visualized as the pathognomonic DNA "ladder." This phenomenon was used as the basis of our pilot studies in RA. Nucleosome-sized fragments were observed in DNA isolated from whole tissue extracts obtained at the time of joint replacement surgery, clearly indicating the presence of apoptosis. However, this technique does not provide information on the location or phenotype of the apoptotic cells. Therefore, an ISEL assay was used to confirm and extend these data by detecting fragmented DNA in situ. Before using this method on synovium, it was first validated using resting and apoptotic HL60 cells. When the same technique was then applied to frozen sections of synovium, all RA synovial tissues showed strong evidence of PCD. The percentage of cells that were positive varied widely among the tissues, with $<5-50 \%$ of cells positive in various regions. OA synovium also had evidence of apoptosis, as did some of the normal synovial tissues. However, the extent of staining in the ISEL assay was significantly less in normal and OA synovium than in RA tissue.

The ISEL method, as well as most other methods of in vitro transcription, do not necessarily distinguish between apoptosis and other causes of DNA fragmentation. The presence of a characteristic DNA ladder on agarose gel electrophoresis suggests that a significant percentage of the in situ labeling occurred on cells undergoing apoptosis, although it is not known whether
ISEL-positive cells are ultimately removed in vivo. Another potential artifact is that the ISEL-positive material might be nuclear debris from dying synovial fluid cells that is phagocytosed by cells in the synovial intimal lining. This is unlikely, however, since it is relatively easy to distinguish cytoplasmic from nuclear labeling when sections are counterstained with hematoxylin or methyl green. Examination of tissues under high power shows that ISEL-positive regions are clearly located within the cell nuclei. Finally, we considered whether some of the DNA fragmentation could be occurring ex vivo. To investigate this, a percutaneous synovial biopsy from an RA patient was immediately snap frozen and examined using ISEL. The distribution and extent of ISEL-positive cells was similar to that of other RA synovia. In addition, the extent of DNA fragmentation in RA synovium as determined by the ISEL method was not significantly increased at least $2 \mathrm{~h}$ after removal from the patient. In other experiments, nonarticular post-mortem tissues (liver and lymph node) were also examined, and none showed evidence of significant labeling. Taken together, these data strongly suggest that the DNA fragmentation identified by ISEL accurately reflects in situ RA synovium.

The most striking evidence for PCD in RA was in the synovial intimal lining, which is comprised of macrophage-like and fibroblast-like synoviocytes. Increased numbers of both cell types contribute to lining hyperplasia in RA, but the percent change in macrophages is thought to be greater. DNA fragmentation was readily detected in this region using the ISEL assay, but the amount of PCD was surprising in light of the previous hypothesis that apoptosis might be low in inflamed synovium (17). The majority of cells with DNA strand breaks in the lining were CD68-positive macrophages. These terminally differentiated cells are derived from the bone marrow and migrate through the blood stream to the synovium (30). While little is known about the dynamics of this process, our data suggest that significant turnover occurs and that the lining is continuously repopulated with less mature macrophages. The relative age of mononuclear phagocytes could have a profound influence on 

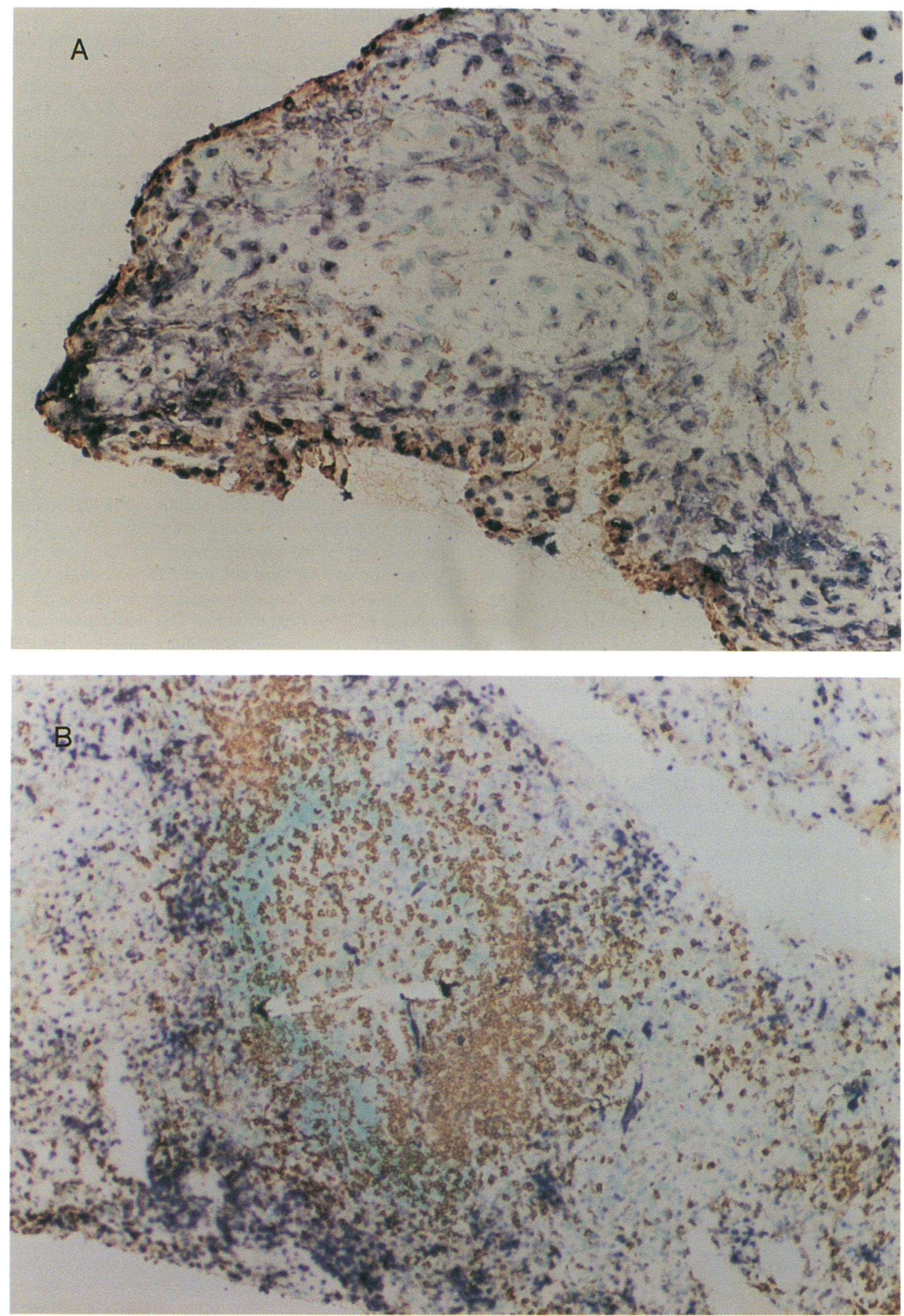

Figure 3. Combination immunohistochemistry and ISEL. Tissues are counterstained with methyl green to show ISEL-negative nuclei. (Brown color $=$ immunoperoxidase stain for cell surface markers; dark purple color $=$ ISEL-positive nuclei; light turquoise color $=$ methyl green stain of ISELnegative nuclei) $(A)$ Tissue stained with anti-CD68 antibody to detect macrophages. The superficial lining layer contains cells that are strongly CD68-positive and ISEL-positive. CD68-negative/ISEL-positive fibroblast-like cells are evident in the deeper layers of the intimal lining; $(B)$ Tissue stained with anti-CD45RO antibody to detect memory $T$ cells. CD45RO positive cells (brown color) in lymphoid aggregates are ISELnegative, although the aggregates are surrounded by ISEL-positive cells. The tissue sections were photographed at a magnification of 200. 
Table I. Location of Apoptotic Cells in Synovial Tissue

\begin{tabular}{llll}
\hline & Intimal lining & Sublining & Blood vessels \\
\hline RA $(n=12)$ & $2.6 \pm 0.1$ & $2.0 \pm 0.2$ & $0.8 \pm 0.2$ \\
OA $(n=4)$ & $1.7 \pm 0.5^{*}$ & $1.0 \pm 0.4^{*}$ & $0.5 \pm 0.3$ \\
Normal $(n=4)$ & $1.0 \pm 0.4^{*}$ & $1.0 \pm 0.4^{*}$ & $0.3 \pm 0.2$
\end{tabular}

$0=$ negative $1+=$ rare positive cells in a specific region;

$2+=$ scattered clusters of positive cells in a specific region;

$3+=$ moderate staining in a specific region; $4+=$ extensive staining in a specific region. $* P<0.05$ compared to $\mathrm{RA}$.

the synovial cytokine profile, since younger macrophages are more likely to produce proinflammatory cytokines like IL-1 while mature cells are biased towards antiinflammatory cytokines like IL-1ra (31). The replacement of senescent macrophages by younger ones could help explain the relative defect in IL-1ra production and the overproduction of IL-1 by synovial macrophages (32).

DNA fragmentation in CD68-negative lining cells was also observed. This, at first, seemed paradoxical in light of data indicating that modest FLS proliferation might contribute to synovial hyperplasia (33). However, apoptosis and cell proliferation can occur simultaneously, a phenomenon likely related to expression of the oncogene c-myc. For instance, introduction of c-myc into fibroblasts increases the rate of apoptosis as well as mitosis (34). c-myc expression in Rat-1 fibroblasts also enhances cell proliferation while down-regulating cell overgrowth through PCD (35). This protective mechanism to prevent excessive expansion of mesenchymal cells appears to correlate with expression of the tumor suppressor gene p53 (36). Since expression of c-myc in the synovial intimal lining is abundant (especially in FLS), this could partially explain the high percentage of apoptotic fibroblast-like lining cells despite evidence of local proliferation (37). Moreover, the mere existence of synovial intimal lining hyperplasia strongly suggests that level of apoptosis in RA, although excessive at first glance, is not sufficient to compensate for local accumulation.

Many sublining cells also stained in the ISEL assay, including macrophages, fibroblasts, $\mathrm{T}$ cells and endothelial cells. One especially prominent finding was the lack of apoptosis in lymphoid aggregates, a phenomenon that correlated with bcl-2 expression in the same region. $\mathrm{Bcl}-2$ is a protooncogene that was first identified in follicular B cell lymphomas and is known to block apoptosis (24-26). This finding is surprising is surprising when one considers that the vast majority of these cells are CD45RO + memory $T$ cells, a phenotype often associated with low bcl-2 expression (6). Continuous restimulation of memory $\mathrm{T}$ cells, either by lymphokines like IL-2 or by products of activated fibroblasts, can prolong survival by maintaining bcl-2 levels or rescuing from apoptosis by as yet undefined mechanisms (6). Since IL-2 levels in the joint are very low (38), the latter explanation seems more likely. Prolonged survival of synovial $\mathrm{T}$ cells by this mechanism could contribute to the marked increase of quiescent memory lymphocytes that do not make lymphokines in the rheumatoid synovium.

The presence of apoptotic CD68-negative synovial lining cells suggested that PCD might occur in cultured FLS, which are thought to be derived from the intimal lining. When a homogeneous population of long-term cultured FLS was studied using the ISEL assay, only a small percentage of resting FLS showed evidence of DNA fragmentation. This was dramatically increased by act $D$, a transcriptional inhibitor known to induce apoptosis in many cell types $(2,3)$. Anti-fas antibody also induced apoptosis, and the fas protein was readily demonstrated on FLS by flow cytometry. IL- 1 and TNF- $\alpha$, which prevent apoptosis in macrophages (39), both induced FLS apoptosis. IFN- $\gamma$ had no effect as a single agent but reduced apoptosis induced by act D, IL-1, or TNF- $\alpha$. This suggests a potential link between the cytokines produced in RA and the propensity for PCD: macrophage and fibroblast products like IL-1 and TNF- $\alpha$ (and quite possibly fas ligand) are abundant in the joint

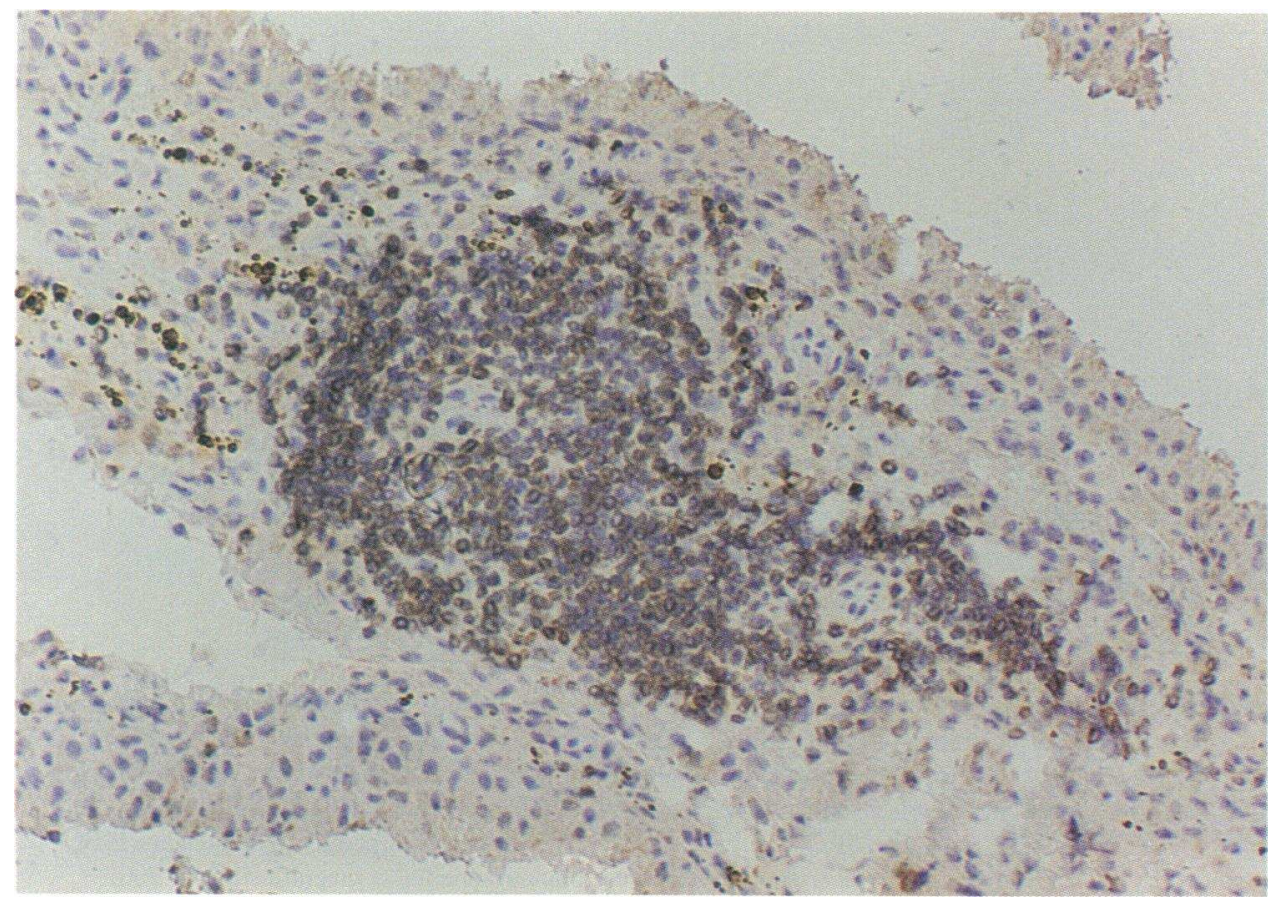

Figure 4. Bcl-2 expression is localized to lymphoid aggregates. Immunohistochemistry shows that bcl-2 expression is minimal in the intimal lining but prominent in lymphoid aggregates containing CD45RO+I CD4+ memory $\mathrm{T}$ cells. The tissue section was photographed at a magnification of 200 . 
Table II. Apoptosis in Cultured Fibroblast-like Synoviocytes

\begin{tabular}{lcc}
\hline \multirow{2}{*}{ Condition } & \multicolumn{2}{c}{ Percentage of apoptotic cells } \\
\cline { 2 - 3 } & Without IFN- $\gamma$ & With IFN- $\gamma$ \\
\hline & & $100 \mathrm{U} / \mathrm{ml}$ \\
Medium & $3 \pm 1$ & $6 \pm 2$ \\
IL-1 $(1 \mathrm{ng} / \mathrm{ml})$ & $50 \pm 2$ & $30 \pm 2^{*}$ \\
TNF- $\alpha(100 \mathrm{ng} / \mathrm{ml})$ & $35 \pm 1$ & $23 \pm 2^{\ddagger}$ \\
Actinomycin D $(0.5 \mu \mathrm{g} / \mathrm{ml})$ & $37 \pm 5$ & $16 \pm 3^{\ddagger}$ \\
Actinomycin D $+\mathrm{TNF}-\alpha$ & $56 \pm 3$ & N.D. \\
Actinomycin D $+\mathrm{IL}-1$ & $56 \pm 5$ & N.D. \\
Anti-fas antibody $(80 \mathrm{ng} / \mathrm{ml})$ & $42 \pm 5$ & N.D. \\
& & \\
\hline
\end{tabular}

FLS were incubated with mediators for $16 \mathrm{~h}(n=3$ separate experiments) in the presence or absence of $100 \mathrm{U} / \mathrm{ml}$ of IFN- $\gamma$. DNA fragmentation was determined with the ISEL assay. $* P=0.057$ compared to IL-1 alone; ${ }^{\ddagger} P<0.03$ compared to TNF- $\alpha$ or actinomycin D alone; N.D., not done.

while IFN- $\gamma$ levels are very low (27). The ability of TNF- $\alpha$ to increase fas expression could also contribute to apoptosis if fas ligand is present in the joint. The cytokine profile of the rheumatoid synovitis (i.e., high IL- 1 and TNF- $\alpha$ and low IFN- $\gamma$ ) therefore favors apoptosis in FLS. Several other aspects of FLS function are also inhibited by IFN- $\gamma$, including TNF- $\alpha$ mediated proliferation, cytokine production, and collagenase production (18).

An alternative intriguing explanation for the induction of apoptosis in RA synovium is based on a recent observation that PCD can be induced in mesenchymal cells like cardiac myocytes by ischemia and reperfusion (40). A similar situation might exist in the joint, where tissue hyperplasia in combination with increased intraarticular pressure can cause severe local hypoxia and acidosis (41). Alternating ischemia and reperfusion in the joint could, therefore, lead to oxygen radical forma-

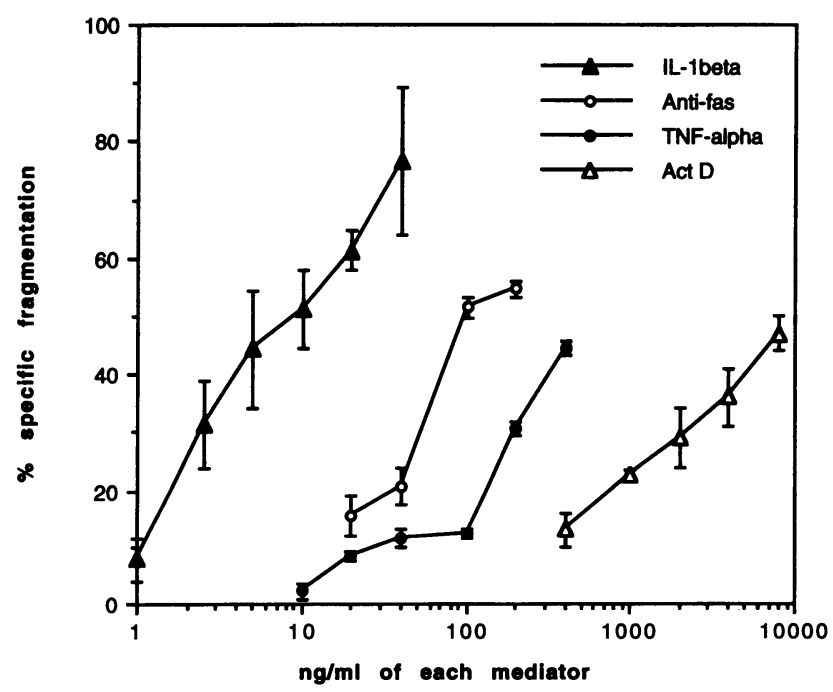

Figure 5. DNA fragmentation in FLS. Cells were treated with various concentrations of act D, anti-fas antibody, IL- $1 \beta$, or TNF- $\alpha$ and the extent of DNA fragmentation was determined by tritiated thymidine incorporation (see Methods). These data correlated well with the ISEL studies performed on FLS cultured in chamber slides (see Table II).

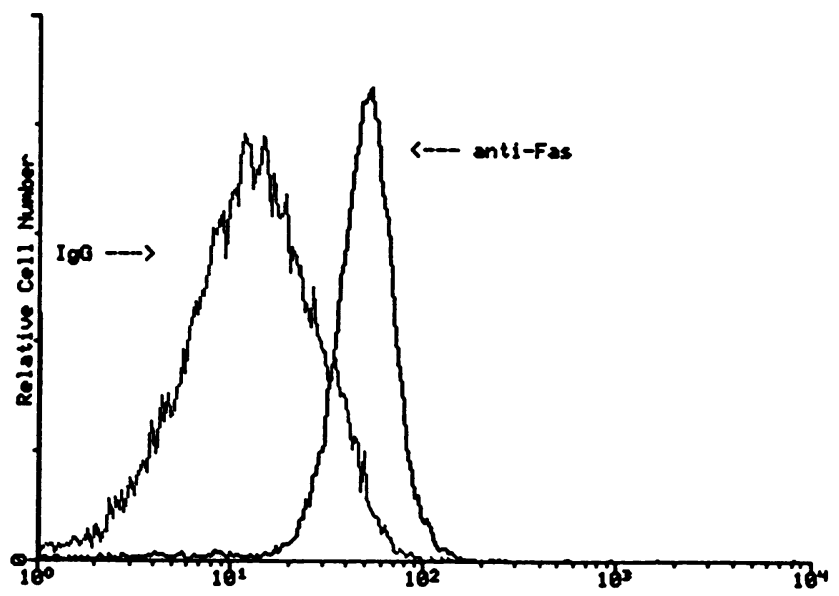

Figure 6. Fas expression on FLS. Long term cultured FLS express fas protein as determined by flow cytometry. The figure shows a histogram from a representative experiment. The vertical axis shows relative cell number and the horizontal axis shows relative red fluorescence. Cells were stained with either anti-fas antibody or control antibody. In the same experiments, FLS were negative using anti-CD68 antibody (data not shown).

tion, DNA fragmentation, and synovial apoptosis. Interestingly, vascular endothelial cells were apoptotic in many RA synovia as well as in the ischemic rabbit myocardium (40). PCD in synovial endothelium could ultimately contribute to tissue ischemia by causing involution of blood vessels.

The presence of PCD in synovium and its regulation by cytokines suggests that apoptosis might be a potential target for therapeutic interventions. However, it is not known whether increasing apoptosis would be beneficial or detrimental in RA. It seems intuitive, based on the histologic features of the disease, that enhanced apoptosis might decrease synovial lining overgrowth or accumulation of T cells. Another potential benefit of increased FLS death might be the local release of the antiinflammatory cytokine IL-1ra. An intracellular form of IL-1ra accumulates within synovial fibroblasts due to alternative splicing of mRNA (32), and apoptosis could be one way to increase synovial tissue concentrations of IL-1ra and thus down-regulate the local inflammatory response. Preliminary studies in vitro support this hypothesis, since act D induces FLS to release some IL-Ira into culture supernatants (presumably by inducing PCD) (Firestein, G. S., M. Yeo, and N. J. Zvaifler, unpublished

Table III. TNF- $\alpha$ Induces Fas Expression on FLS

\begin{tabular}{lcc}
\hline \multicolumn{1}{c}{ Condition } & Relative MFC & Percentage of positive \\
\hline Medium & 1.00 & $39 \pm 7$ \\
TNF- $\alpha$ & & \\
$100 \mathrm{ng} / \mathrm{ml}$ for $16 \mathrm{~h}$ & $1.66 \pm 0.20^{*}$ & $66 \pm 6^{*}$ \\
$100 \mathrm{ng} / \mathrm{ml}$ for $24 \mathrm{~h}$ & $1.82 \pm 0.31^{*}$ & $66 \pm 8^{*}$ \\
IL-1 $\beta$ & & \\
$1 \mathrm{ng} / \mathrm{ml}$ for $16 \mathrm{~h}$ & $1.17 \pm 0.05$ & $52 \pm 7$ \\
$1 \mathrm{ng} / \mathrm{ml}$ for $24 \mathrm{~h}$ & $1.34 \pm 0.21$ & $46 \pm 6$ \\
\hline
\end{tabular}

* $P<0.05$ compared with medium control. Relative $\mathrm{MFC}=\left(\mathrm{MFC}_{\text {cytokine }}\right.$ $\left.-\mathrm{MFC}_{\mathrm{IgG}}\right) /\left(\mathrm{MFC}_{\text {medium }}-\mathrm{MFC}_{\mathrm{IgG}}\right)$. FLS were cultured with medium or cytokines for the specified period and analyzed by flow cytometry. $n=6$ (three OA and three RA lines). 
data). Agents that enhance apoptosis could, therefore, serve a dual purpose of decreasing synovial hyperplasia and increasing release of antiinflammatory cytokines.

\section{Acknowledgments}

The authors thank Aung Lwin for expert technical assistance and Dennis Young for performing flow cytometry.

This work was supported in part by National Institutes of Health grants AR 40525, AR 40770, and AR 07062.

\section{References}

1. Cotter, T. G., S. V. Lennon, J. G. Glynn, and S. J. Martin. 1991. Cell death via apoptosis and its relationship to growth, development and differentiation of both tumour and normal cells. Anticancer Res. 10:1153-1160.

2. Leist, M., F. Gantner, I. Bohlinger, P. G. Germann, G. Tiegs, and A. Wendel. 1994. Murine hepatocyte apoptosis induced in vitro and in vivo by TNFalpha requires transcriptional arrest. J. Immunol. 153:1778-1788.

3. Lennon, S. V., S. J. Martin, and T. G. Cotter. 1990. Induction of apoptosis (programmed cell death) in tumour cell lines by widely diverging stimuli. Biochem. Soc. Trans. 18:343-345.

4. Itoh, N., S. Yonehara, A. Ishii, M. Yonehara, S. Mizushima, M. Sameshima, A. Hase, Y. Seto, and S. Nagata. 1991. The polypeptide encoded by the cDNA for human cell surface antigen Fas can mediate apoptosis. Cell. 66:233-243.

5. Mangan, D. F., and S. M. Wahl. 1991. Differential regulation of human monocyte programmed cell death (apoptosis) by chemotactic factors and proinflammatory cytokines. J. Immunol. 147:3408-3412.

6. Akbar, A. N., N. Borthwick, M. Salmon, W. Gombert, M. Bofill, N. Shamsadeen, D. Pilling, S. Pett, J. E. Grundy, and G. Janossy. 1993. The significance of low bcl-2 expression by CD45RO T cells in normal individuals and patients with acute viral infections. The role of apoptosis in T cell memory. J. Exp. Med. 178:427-438.

7. D'Adamio, L., K. M. Awad, and E. L. Reinherz. 1993. Thymic and peripheral apoptosis of antigen-specific $\mathrm{T}$ cells might cooperate in establishing self tolerance. Eur. J. Immunol. 23:747-753.

8. Owen, J. J., and E. J. Jenkinson. 1992. Apoptosis and T-cell repertoire selection in the thymus. Ann. NY Acad. Sci. 663:305-310.

9. Hogquist, K., M. A. Nett, E. R. Unanue, and D. D. Chaplin. 1991. Interleukin 1 is processed and released during apoptosis. Proc. Natl. Acad. Sci. USA 88:8485-8489.

10. Zychlinsky, A., C. Fitting, J.-M. Cavaillon, and P. J. Sansonetti. 1994 Interleukin 1 is released by murine macrophages during apoptosis induced by Shigella flexneri. J. Clin. Invest. 94:1328-1332.

11. Watson, M. L., J. K. Rao, G. S. Gilkeson, P. Ruiz, E. M. Eicher, D. S. Pisetsky, A. Matsuzawa, J. M. Rochelle, and M. F. Seldin. 1992. Genetic analysis of MRL-lpr mice: relationship of the Fas apoptosis gene to disease manifestations and renal disease-modifying loci. J. Exp. Med. 176:1645-1656.

12. Takahashi, T., M. Tanaka, C. I. Brannan, N. A. Jenkins, N. G. Copeland, T. Suda, and S. Nagata. 1994. Generalized lymphoproliferative disease in mice, caused by a point mutation in the Fas ligand. Cell. 76:969-976.

13. Cheng, J., T. Zhou, C. Liu, J. P. Shapiro, M. J. Brauer, M. C. Kiefer, P. J. Barr, and J. D. Mountz. 1994. Protection from Fas-mediated apoptosis by a soluble form of the Fas molecule. Science (Wash. DC). 263:1759-1762.

14. Emlen, W., J. Niebur, and R. Kadera. 1994. Accelerated in vitro apoptosis of lymphocytes from patients with systemic lupus erythematosus. J. Immunol. 152:3685-3692.

15. Jones, S. T., J. Denton, P. J. Holt, and A. J. Freemont. 1993. Possible clearance of effete polymorphonuclear leucocytes from synovial fluid by cytophagocytic mononuclear cells: implications for pathogenesis and chronicity in inflammatory arthritis. Ann. Rheum. Dis. 52:121-126.

16. Martin, T. I., T. J. Pekin, and N. J. Zvaifler. 1967. Cytology of synovial fluid in rheumatoid arthritis. Am. J. Clin. Pathol. 47:203-208.

17. Mountz, J. D., J. Wu, J. Cheng, and T. Zhou. 1994. Autoimmune disease: a problem of defective apoptosis. Arthritis Rheum. 37:1415-1420.

18. Alvaro-Gracia, J. M., N. J. Zvaifler, and G. S. Firestein. 1990. Cytokines in chronic inflammatory arthritis. V. Mutual antagonism between interferongamma and tumor necrosis factor-alpha on HLA-DR expression, proliferation, collagenase production, and granulocyte macrophage colony-stimulating factor production by rheumatoid arthritis synoviocytes. J. Clin. Invest. 86:1790-1798.

19. Firestein, G. S., M. M. Paine, and D. L. Boyle. 1994. Mechanisms of methotrexate action in rheumatoid arthritis. Selective decrease in synovial collagenase gene expression. Arthritis Rheum. 37:193-200.

20. Wood, K. A., B. Dipasquale, and R. J. Youle. 1993. In situ labeling of granule cells for apoptosis-associated DNA fragmentation reveals different mechanisms of cell loss in developing cerebellum. Neuron. 11:621-632.

21. Wijsman, J. H., R. R. Jonker, R. Keijzer, C. J. van de Velde, C. J. Cornelisse, and J. H. van Dierendonck. 1993. A new method to detect apoptosis in paraffin sections: in situ end-labeling of fragmented DNA. J. Histochem. Cytochem. 41:7-12.

22. Morales-Ducret, J., E. Wayner, M. J. Elices, J. M. Alvaro-Gracia, N. J. Zvaifler, and G. S. Firestein. 1992. Alpha 4/beta 1 integrin (VLA-4) ligands in arthritis. Vascular cell adhesion molecule-1 expression in synovium and on fibroblast-like synoviocytes. J. Immunol. 149:1424-1431.

23. Matzinger, P. 1991. The JAM test. A simple assay for DNA fragmentation and cell death. J. Immunol. Methods. 145:185-192.

24. Itoh, N., Y. Tsujimoto, and S. Nagata. 1993. Effect of bcl-2 on fas antigenmediated cell death. J. Immunol. 151:621-627.

25. Korsmeyer, S. J. 1992. Bcl-2 initiates a new category of oncogenes: regulators of cell death. Blood. 80:879-886.

26. Hockenbery, D. M., Z. N. Oltvai, X. M. Yin, C. L. Milliman, and S. J. Korsmeyer. 1993. Bcl-2 functions in an antioxidant pathway to prevent apoptosis. Cell. 75:241-251.

27. Firestein, G. S., and N. J. Zvaifler. 1990. How important are T cells in chronic rheumatoid synovitis? Arthritis Rheum. 33:768-773.

28. Cronstein, B. N., and G. Weissmann. 1993. The adhesion molecules of inflammation. Arthritis Rheum. 36:147-157.

29. Koch, A. E., J. C. Burrows, G. K. Haines, T. M. Carlos, J. M. Harlan, and S. J. Leibovich. 1991. Immunolocalization of endothelial and leukocyte adhesion molecules in human rheumatoid and osteoarthritic synovial tissues. Lab. Invest. 64:313-320.

30. Mapp, P. I., and P. A. Revell. 1988. Ultrastructural characterisation of macrophages (type A cells) in the synovial lining. Rheumatol. Int. 8:171-176.

31. Arend, W. P., M. F. Smith, Jr., R. W. Janson, and F. G. Joslin. 1991. IL1 receptor antagonist and IL-1 beta production in human monocytes are regulated differently. J. Immunol. 147:1530-1536.

32. Firestein, G. S., D. L. Boyle, C. Yu, M. M. Paine, T. D. Whisenand, N. J. Zvaifler, and W. P. Arend. 1994. Synovial interleukin-1 receptor antagonist and interleukin-1 balance in rheumatoid arthritis. Arthritis Rheum. 37:644-652.

33. Qu, Z., C. H. Garcia, L. M. O'Rourke, S. R. Planck, M. Kohli, and J. T. Rosenbaum. 1994. Local proliferation of fibroblast-like synoviocytes contributes to synovial hyperplasia. Results of proliferating cell nuclear antigen/cyclin, cmyc, and nucleolar organizer region staining. Arthritis Rheum. 37:212-220.

34. Arends, M. J., A. H. McGregor, N. J. Toft, E. J. Brown, A. H. Wyllie. 1993. Susceptibility to apoptosis is differentially regulated by c-myc and mutated Ha-ras oncogenes and is associated with endonuclease availability. Br. J. Cancer. 68:1127-1133.

35. Evans, G. I., A. H. Wyllie, G. S. Gilbert, T. D. Littlewood, J. Land, M. Brooks, C. M. Waters, L. Z. Penn, and Hancock. 1992. Induction of apoptosis in fibroblasts by c-myc protein. Cell. 69:119-128.

36. Hermeking, H., and D. Eick. 1994. Mediation of c-myc-induced apoptosis by p53. Science (Wash. DC). 265:2091-2093.

37. Ritchlin, C., E. Dwyer, R. Bucala, and R. Winchester. 1994. Sustained and distinctive patterns of gene activation in synovial fibroblasts and whole synovial tissue obtained from inflammatory synovitis. Scand. J. Immunol. 40:292298.

38. Firestein, G. S., W. D. Xu, K. Townsend, D. Broide, J. Alvaro-Gracia, A. Glasebrook, and N. J. Zvaifler. 1988. Cytokines in chronic inflammatory arthritis. I. Failure to detect T cell lymphokines (interleukin 2 and interleukin 3 ) and presence of macrophage colony-stimulating factor (CSF-1) and a novel mast cell growth factor in rheumatoid synovitis. J. Exp. Med. 168:1573-1586.

39. Mangan, D. F., G. R. Welch, and S. M. Wahl. 1991. Lipopolysaccharide, tumor necrosis factor-alpha, and IL-1 beta prevent programmed cell death (apoptosis) in human peripheral blood monocytes. J. Immunol. 146:1541-1546.

40. Gottlieb, R. A., K. O. Burleson, R. A. Kloner, B. M. Babior, and R. L. Engler. 1994. Reperfusion injury induces apoptosis in rabbit cardiomyocytes. J. Clin. Invest. 94:1621-1628.

41. Edmonds, S. E., D. R. Blake, C. J. Morris, and P. G. Winyard. 1993. An imaginative approach to synovitis: the role of hypoxic reperfusion damage in arthritis. J. Rheumatol. $37 \mathrm{~S}: 26-31$. 